\title{
Razão à sombra do sexismo: o feminino no pensamento de Sêneca
}

\author{
Taynam Santos Luz Bueno ${ }^{1}$
}

\begin{abstract}
Resumo: Neste artigo será abordada a ambígua e, por vezes, contraditória representação das mulheres no pensamento do filósofo estoico Sêneca. Com isso, pretende-se demonstrar que a construção da postura misógina no âmbito da filosofia se dá, primeiramente, desde a antiguidade e, muitas vezes, de modo conflituoso com os próprios pressupostos e princípios professados pelas diversas correntes de pensamento. No caso específico deste texto, pretendemos demonstrar como Sêneca, declarado filósofo estoico, apresenta o gênero feminino de modo pejorativo e, como veremos, com discutível respaldo no conjunto dos princípios da filosofia do pórtico. Ao acompanhar as reflexões do pensador romano sobre o gênero feminino percebemos que há uma dupla apresentação das mulheres. Em algumas passagens, o filósofo as expõe como virtuosas e, portanto, dignas da atividade filosófica e da realização de ações corretas. Por outro lado, e na maior parte das vezes, o autor latino confere ao gênero feminino características que indicam limitações e podem prejudicar seu comportamento ético, mitigando assim o exercício pleno de sua racionalidade. Por muitas vezes, vemos Sêneca associar aos adjetivos femininos falhas morais e deficiências de caráter, ao passo que, aos adjetivos masculinos, o filósofo creditará ações virtuosas e ligadas à racionalidade. No entanto, como compreender tal ambiguidade em relação ao gênero feminino se, por princípio, o pensamento estoico afirma que a potencialidade de realização de ações virtuosas é garantida à humanidade, graças a sua participação na razão universal?
\end{abstract}

Palavras-chave: Mulheres - Racionalidade - Estoicismo - Sêneca - Sexismo

\section{Reason in the shadow of sexism: the feminine in Seneca's thought}

\begin{abstract}
In this article we will address the ambiguous and sometimes contradictory representation of women in the thought of the Stoic philosopher Seneca. With this, we want to show that the construction of the misogynist posture in philosophy takes place, first, since antiquity and, often in conflict with the presuppositions and principles professed by the different currents of thought. In the specific case of this text, we intend to show how Seneca, a stoic philosopher, presents the female gender in a derogatory way and, as we shall see, with arguable support in the set of principles of stoic philosophy. By following the reflections of the Roman thinker on the feminine gender, we realize that there is a double presentation of women. In some passages, the philosopher exposes them as virtuous and, therefore, worthy of philosophical activity and capable of good deeds. On the other hand, and most of the time, the Latin author gives the feminine gender characteristics that indicate limitations and can impact their ethical behavior, thus impairing the full exercise of their rationality. Many times, we see Seneca associate feminine adjectives to moral flaws and character deficiencies, while masculine adjectives are associated with virtuous actions linked to rationality. Nevertheless, how to understand such ambiguity in relation to the female gender if, in principle, the Stoic thought upholds that the potentiality of performing virtuous actions is guaranteed to humanity due to its participation in universal reason?
\end{abstract}

Keywords: Women - Rationality - Stoicism - Seneca - Sexism

${ }^{1}$ Professora Adjunta na Universidade Federal de Alagoas - UFAL. E-mail: taynambueno@hotmail.com 
Para compreendermos exatamente o que estamos chamando de sexismo no pensamento senequiano, termo certamente anacrônico frente à problemática da filosofia antiga, retomaremos brevemente alguns pontos fundamentais do estoicismo no que diz respeito ao exercício da racionalidade e, portanto, à possibilidade de filosofar e tomar acertadamente decisões éticas. Faremos isso para expor e problematizar o modo como Sêneca representa o gênero feminino em seus diálogos, apontando para as diversas tensões entre a representação fornecida e os preceitos da stoa. Nosso intuito principal não é acusar o autor latino de preconceito ou misoginia, muito menos condená-lo por não ter se debruçado em questões que não se colocam no contexto histórico do filósofo. Nossa intenção é demonstrar como as mulheres, desde muito cedo na história da filosofia, são caracterizadas pejorativamente por meio de uma injustificada desqualificação de sua racionalidade e constante rebaixamento de suas produções e atividades intelectuais. Além disso, pretendemos ilustrar que, muitas vezes, este movimento é realizado em desacordo com os próprios princípios filosóficos que norteiam seus autores. Portanto, não é nosso objetivo, neste artigo, defender ou não a existência de um "feminismo" estoico, haja visto que tal problemática é anacrônica ao pensamento antigo, já existindo bons trabalhos que abordam tal questão. Nosso intuito é tentar compreender e interpretar a contradição entre afirmar a universalidade da racionalidade humana e, ao mesmo tempo, associar ao gênero feminino, características que são opostas à razão, como nos parece fazer Sêneca. Assim, pretendemos indicar o valor negativo dos atributos associados à natureza das mulheres e ao mesmo tempo propor uma reflexão a respeito da incompatibilidade que isso gera em relação a algumas premissas do estoicismo.

Assim, vejamos primeiramente o que Sêneca afirma a respeito da universalidade da razão e do lugar privilegiado ${ }^{2}$ dos seres humanos na natureza. Faz parte dos pressupostos mais fundamentais da escola estoica afirmar que todos os homens [e mulheres], apenas pelo fato de pertencerem ao gênero humano, são partícipes da razão universal e, por o fazerem ativamente, ocupam um lugar especial na ordem natural. Os homens são, portanto, capazes de agir corretamente graças ao exercício de sua racionalidade. O que isso significa? Que todo aquele que pertence a este conjunto possui racionalidade, sendo assim capaz de tomar decisões, fazer escolhas e deliberar entre o vício e a virtude, ou seja; ao ente dotado de razão é facultado escolher o caminho da virtude e o afastamento dos vícios.

Deste modo, os pensadores da Stoá, incluído aí o próprio Sêneca, afirmam que homens, mulheres, escravos, ricos, pobres, estrangeiros; enfim, todo a espécie humana, possui, ao menos potencialmente, as mesmas capacidades de realização da vida feliz. Todos teriam, de acordo com as palavras de nosso autor, igual capacidade para o exercício filosófico e para a vida virtuosa, pois, para a sabedoria, "todos somos de nascimento nobre. A filosofia

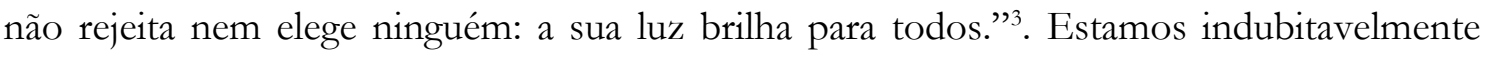
diante de uma corrente filosófica, neste sentido bastante progressista, que afirma a universalidade da razão apesar de quaisquer qualidades particulares ou distintivos sociais que possam existir entre os agentes, haja vista que toda a humanidade partilha da mesma semente

\footnotetext{
${ }^{2}$ Conferir por exemplo SÊNECA, Ep., 92, 27-30 e Ep. 124, 14. Salvo indicação contrária, as passagens dos autores antigos serão abreviadas de acordo com a notação proposta pelo Oxford Classical Dictionary.

${ }^{3}$ SÊNECA, Ep., 44, 2.
} 
de racionalidade e, "a todos nós a natureza deu, em potência, a semente da virtude." ${ }^{4}$ Ainda nas palavras de Sêneca, "De tudo quanto é honesto o nosso espírito contém em si as sementes" ". A virtude, diz o filósofo estoico, não é restrita a nenhum grupo específico, visto que todo o gênero humano, por ser partícipe da racionalidade, sem distinção de sexo, condição, atributo físico ou classe social, poderia alcançá-la, desde que escolhesse viver de acordo com a Natureza ${ }^{6}$.

Diante desta profissão de universalidade da razão, podemos mesmo afirmar que o estoicismo, incluído aí o pensamento de Sêneca, se apresentou bastante benevolente em relação às diferenças e particularidades existentes entre os homens, apresentando talvez esboços de uma teoria humanista, já na antiguidade ${ }^{7}$ É o caso, por exemplo, da crítica do autor romano direcionada às sevícias cometidas contra prisioneiros, gladiadores e escravos ${ }^{8}$, que, segundo Sêneca, deveriam ser rechaçadas uma vez que, reconhecida a universalidade da razão, o homem devia ser coisa sagrada ao próprio homem ${ }^{2}$ Este reconhecimento é, ao menos do ponto de vista dos princípios, estendido às mulheres. É o que podemos ler em algumas afirmações do filósofo romano que colocam, em pé de igualdade, homens e mulheres no tocante a vida virtuosa, como exposto na obra Consolação a Márcia ${ }^{10}$. Diz Sêneca:

Porém quem terá dito que a natureza agiu mesquinhamente com o espírito das mulheres e limitou ao corpo as suas virtudes? Acredita-me, elas têm o mesmo vigor, a mesma força para as coisas honestas, quando querem; desde que tenham se acostumado elas suportam, igualmente, a dor e o trabalho. ${ }^{11}$

$\mathrm{Na}$ passagem acima, Sêneca ressalta que as mulheres podem, quando querem e são instruídas para isso, agir com virtude. A natureza (natura) ofereceu, segundo o autor, iguais condições de exercício da racionalidade aos homens e às mulheres. Nesta citação específica, o autor reafirma que Márcia, mesmo sendo mulher, pode suportar a dor da morte de um ente querido e, para ilustrar tal afirmação, traz à tona um conjunto de exemplos de outras mulheres que, em situações semelhantes agiram de modo decoroso e "suportaram fortemente a morte dos seus" 12 . Neste e em outros textos, nosso autor traz outros exemplos nos quais relata ações moralmente positivas das mulheres. Entre os exemplos de honrosas

\footnotetext{
${ }^{4}$ SÊNECA, Ep., 108, 8. É preciso notar que os estoicos excluem da categoria de "racionais" os loucos e as crianças até os sete anos de idade (para alguns filósofos até os 14 anos). Sobre as crianças, pelo claro motivo de não ter suas capacidades racionais plenamente ativas, pois ainda estão em processo de desenvolvimento. A infância é, portanto, um estado de imperfeição e incompletude. Já os loucos não podem compor este grupo por não serem capazes de julgar corretamente em decorrência de uma doença ou falha em sua alma. C.f.: SÊNECA. Ep. 121, 15. L\&S (Abreviação para A.A. LONG \& D. N. SEDLEY) 39E e 54H; bem como Diog. Laert., Livro VII, 55-56.

${ }^{5}$ SÊNECA, Ep. 94, 29.

${ }^{6}$ SÊNECA, Ep. 95,52 e Ben. III, 18, 2.

${ }^{7}$ Esta é a tese de Müller que afirma, por exemplo, que os estoicos são grandes influenciadores das ideias humanistas desenvolvidas na modernidade. In: MÜLLER, R. Les Stoïciens: La liberté et l'ordre du monde. Paris: VRIN, 2006. p.109.

8 SÊNECA, Ep. 7 e Ep. 47.

${ }^{9}$ SENNECA, Ep. 95, 33.

10 SÊNECA, Consolação à Marcia. Um fato interessante a notar é que Sêneca, diferentemente de outros autores do estoicismo, endereça duas consolações a mulheres. O filósofo escreve para sua mãe, Helvia, consolando-a acerca de seu próprio exílio; bem como consola Márcia, que acaba de perder um filho.

${ }^{11}$ SÊNECA, Consolatio ad Marciam. 16, 1-2.

12 SÊNECA, Consolatio ad Marciam. 16, 3.
} 
damas, temos o caso da própria mãe de Sêneca, Hélvia, exaltada em sua consolação por sua força de caráter e por não sucumbir às fraquezas femininas [muliebri impotentia] ${ }^{13}$, como era de se esperar normalmente naquela sociedade. É também o caso de Cornélia, mãe dos irmãos Graco $^{14}$, de Rutília, da já citada Márcia e de Lívia, esposa do imperador Augusto. Sobre esta última, Sêneca chega a lhe apresentar, no De Clementia, como boa conselheira e mulher austera e prudente, isto é, mulher que cumpre seu papel social com decoro e, portanto, com o esperado pela sociedade romana do primeiro século.

A ambiguidade que gostaríamos de apontar diz respeito ao modo como esta imagem positiva, fornecida em alguns exemplos, contrasta com a maioria das representações que Sêneca fornece do gênero feminino. É essencial perceber que, apesar dos elogios existentes, a imagem geral da mulher e do gênero feminino, que sobressai na obra senequiana, está atrelada à característica negativa. Mesmo quando Sêneca exorta o comportamento feminino, são oferecidos casos específicos; exceções que somente servem para, por seu exemplum, confirmar a regra geral da debilidade do caráter feminino ${ }^{15}$. Assim, diante do majoritário quadro de exemplos indecorosos, Sêneca elenca algumas mulheres que, diante de suas impotências e fraquezas, lutaram e agiram virtuosamente, apesar de serem mulheres. Mas, devemos reiterar e deixar bem claro, eram mulheres excepcionais. Num panorama geral, podemos afirmar que, no pensamento senequiano, as mulheres são regularmente vinculadas às ações passionais, de tal modo que, por repetição, é traçada uma imagem que lhes diferencia enquanto grupo. Em primeiro lugar, os exemplos positivos envolvendo as mulheres são mais escassos que os de homens; natural se pensarmos no papel desempenhado pelas mulheres no primeiro século de nossa era e no pouco protagonismo social que tinham. No entanto, o que realmente inquieta é notar que a imagem típica da mulher é, para Sêneca, ligada aos excessos, à instabilidade e à passionalidade, fato que ao mesmo tempo que parece contradizer os pressupostos estoicos ligados à universalidade do exercício racional, comum a todo o gênero humano, também exemplifica bem o sexismo existente, desde a antiguidade, no campo científico e filosófico.

Em alguns trechos, tal representação da figura feminina ganha verdadeiro destaque, na exata medida em que o autor romano escolhe adjetivações depreciativas de modo contundente, atribuindo à natureza particular das mulheres características que lhe são frequentes. Na passagem abaixo fica evidente o vínculo entre as mulheres e seu frágil julgamento, passagem na qual Sêneca aponta para a existência de uma natureza específica e inerente ao gênero feminino.

De certas ofensas somos nós mesmos testemunhas. Nelas deveremos investigar a natureza e a intenção daqueles que as praticam. É uma criança: faça-se concessão a sua idade, ela não sabe se está agindo mal. É um pai: ou ele nos foi tão

\footnotetext{
${ }^{13}$ SÊNECA, Helv., 14, 2.

14 Alguns exemplos de boas mulheres são apresentados, por exemplo, em SÊNECA, Helv., 16, 6-7.

${ }^{15}$ Há uma grande diferença, no pensamento senequiano, acerca da questão da igualdade de sexos. Se na Consolatio ad Marciam é admitida certa igualdade entre os sexos, no De Clementia, De Constatia Sapientis e no De Ira, a desigualdade entre homens e mulheres é patente.
} 
benéfico que tem até o direito de nos injuriar, ou talvez seja uma mercê o motivo por que somos ofendidos. É uma mulher: ela erra. ${ }^{16}$

$\mathrm{Na}$ afirmação acima, o autor apresenta o erro de juízo como um traço tipicamente feminino, inerente à sua natureza, o que corrobora para o reconhecimento de uma particularidade das mulheres, a despeito das premissas que declaram a universalidade da razão. Há, portanto, a construção de traços distintivos entre homens e mulheres, de modo a opor sistematicamente estes dois grupos, associando a racionalidade ao universo masculino, ao passo que as paixões, a destemperança, o descontrole e os erros de julgamento são comumente ligados à mulher. As constantes predicações utilizadas pelo filósofo contribuem, assim, para a formação de uma regularidade "identitária" que perdurou no tempo. Para o autor, muitas mulheres são arrogantes, fúteis, vaidosas, ferozes, obstinadas, ignóbeis, ambiciosas, destemperadas e pouco potentes contra as paixões, o que faz com que recaiam com maior frequência no vício e sejam comumente criticadas pelo filósofo ${ }^{17}$. Diz Sêneca:

É próprio de uma grande alma ser calma e tranquila, e olhar de cima as injúrias e ofensas. Cabe à mulher perder a cabeça de raiva; é próprio de animais ferozes, e certamente dos de não boa raça, morder e estraçalhar as vítimas prostradas. Elefantes e leões prosseguem seu caminho por entre os que abateram; a obstinação é própria do animal ignóbil. ${ }^{18}$

As mulheres, de acordo com Sêneca, são consideradas imprudentes e imperitae. Elas são mais suscetíveis que os homens, são facilmente perturbáveis e, diante das adversidades, elas entregam-se mais facilmente às paixões, chorando por muito mais tempo ${ }^{19}$, por exemplo. São ainda seres instintivos e, na maioria dos casos, não possuem a virilidade e o autocontrole necessários à vida virtuosa e ao exercício filosófico. Como afirma o filósofo, as mulheres comumente não "aceitam o controle da razão"20. Além disso, as mulheres são constantemente rebaixadas do ponto de vista intelectual, associadas ao comportamento insano ou colocadas no mesmo patamar argumentativo das crianças. No De Ira, temos mais um exemplo desta caracterização feminina. Diz nosso autor que "a ira é um vício típico, sobretudo, da mulher e da criança." 21

Ademais, Sêneca também faz questão de frisar sempre que os elogios, críticas e conselhos tecidos por mulheres (e crianças) não têm o mesmo valor que os emitidos por homens adultos ${ }^{22}$. Em suma, os juízos e posicionamentos femininos não podem ser levados a sério, motivo pelo qual não se deve deixar ressentir com as injúrias por elas cometidas ${ }^{23}$. Diz o autor:

\footnotetext{
16 SÊNECA, De Ira. II, 30, 1. Em Latim: "Quorundam ipsi testes sumus: in his naturam excutiemus uoluntatemque facientium. Puer est: aetati donetur, nescit an peccet. Pater est: aut tantum profuit ut illi etiam iniuriae ius sit, aut fortasse ipsum hoc meritum eius est quo offendimur. Mulier est: errat.”

${ }_{17}$ SÊNECA, Helv., 14,2 e 17. Ver outros exemplos em SÊNECA, Ep. 104, 27 e Constant., 18, 6.

18 SÊNECA, Clem., I, 5, 5.

${ }^{19}$ SÊNECA, Ep. 63,13.

${ }^{20}$ FAVEZ, "Les opinions de Sénèque sur la femme", p. 336.

${ }^{21}$ SÊNECA, De Ira. I, 20. Conferir Clem. I, 5, 5 e Ep. 29,12.

22 SÊNECA, Ep. 29, 12. Também Ep. 88, 2.

${ }^{23}$ FAVEZ, "Les opinions de Sénèque sur la femme”, p. 336.
} 
Tamanha demência domina alguns a ponto de acharem que uma contumélia lhes pode ser feita por uma mulher. Que importa quanto a consideram abastada, quantos lecticários tenha, quão adornada as suas orelhas, quão espaçosa a sua liteira? Igualmente é uma criatura imponderada [aeque inprudens animal est], e, se não the advieram conhecimento e muita erudição, é feroz, incontinente nos desejos. ${ }^{24}$

Já no De Clementia, Sêneca nos relata que as mulheres são especialmente vulneráveis frente aos infortúnios alheios, cedendo mesmo diante dos piores criminosos e, portanto, sucumbindo às paixões e ao vício na aplicação das penas:

Portanto, do mesmo modo com a religião honra os deuses, a superstição os ultraja, assim todo homem de bem oferecerá clemência e mansidão, e evitará a compaixão, porque é falha de um espírito pusilânime sucumbir à vista dos infortúnios alheios. Assim, esta atitude é muito comum entre os que estão nas piores condições. Existem velhas e mulherzinhas que se comovem com as lágrimas dos maiores criminosos e que, caso fosse permitido, lhes arrombariam a porta do cárcere. A compaixão não observa a causa do castigo, mas o infortúnio do criminoso. A clemência se aproxima da razão. ${ }^{25}$

Temos, portanto, expressa nesta passagem senequiana, uma típica reprovação moral das mulheres feita em função de seu caráter passional. Sobre o trecho acima, comenta Favez:

A reprovação, como vimos, recai sobretudo na palavra compaixão, que denota uma sensibilidade efetivamente mais feminina que masculina, uma sensibilidade cega, que não se importa em saber se o objeto ao qual ela se aplica é verdadeiramente digno. ${ }^{26}$

Assim, para Sêneca, as mulheres julgam mal. Deixam-se comover e não agem, portanto, de modo racional. Além disso, do ponto de vista da escolha vocabular de Sêneca, há um curioso dado a se notar: há uma clara preferência do autor por adjetivos masculinos quando esse deseja enaltecer comportamentos e ações. Em contrapartida, as adjetivações femininas são majoritariamente utilizadas para reprovar ações, hábitos e costumes. Por exemplo, ao contrário da impotentia associada às mulheres, temos a posição firme e imperturbável associada à virilidade.

Sobre esta deliberada escolha vocabular do filósofo romano para se referir aos homens e às mulheres, afirma Manning que "Sêneca, em seus escritos, impõe o adjetivo muliebris associado às falhas morais, enquanto virilis associado às filosofias e ações que ele aprova." ${ }^{27}$ Muliebris é, portanto, sempre utilizado para desprezar ou condenar ações do ponto

${ }^{24}$ SÊNECA, De Constantia, 14, 1. Em latim: "Tanta quosdam dementia tenet ut sibi contumeliam fieri putent posse a muliere. Quid refert quam $<$ beatam $>$ habeant, quot lecticarios habentem, quam oneratas aures, quam laxam sellam? aeque inprudens animal est et, nisi scientia accessit ac multa eruditio, ferum, cupiditatium incontinens."

${ }^{25}$ SÊNECA, Clem., II, 5, 1.

${ }^{26}$ FAVEZ, "Les opinions de Sénèque sur la femme", p. 336.

${ }^{27}$ MANNING, "Seneca and the stoics on the equality of the sexes", p. 171. 
de vista moral. Vale lembrar que o próprio termo latino virtus (virtude) deriva de vir, isto é, da palavra homem ${ }^{28}$, fato que Sêneca utiliza muito bem a favor de seus argumentos, como bom orador que é.

Outro fato a se notar é que os elogios às mulheres são muito mais raros se comparados com as críticas que recebem ${ }^{29}$. Constantemente Sêneca refere-se à filosofia estoica elogiosamente como um "uma rígida e viril sabedoria" (stoicorum rigida ac virilis sapientia) ${ }^{30}$, diferenciando o estoicismo de outras escolas filosóficas, repetidamente associadas à mulher, ao gênero feminino, à passividade e ao comportamento efeminado ${ }^{31}$. É este gênero de diferenciação que vemos expresso na comparação que Sêneca faz entre estoicos e epicuristas. Diz o autor:

Entre os estoicos e outros mestres de filosofia, Sereno, eu diria, não sem razão, que há tanta diferença quanto entre mulheres e homens, dado que uns e outros contribuem no mesmo tanto para a vida em sociedade, mas uns teriam nascido para obedecer, outros, para mandar. ${ }^{32}$

Ora, diante deste panorama de representação das mulheres e distinção do gênero feminino nos diálogos senequianos, como compreender a tensão entre a potencial universalidade da razão e a desqualificação racional constantemente atrelada às mulheres no pensamento de Sêneca? As possíveis respostas podem ser indicadas em duas direções diferentes: 1. Na crítica de Sêneca direcionada aos insensatos em geral; 2. Na expressão pura e simples de sexismo e misoginia.

Tratemos primeiramente daquilo que chamamos aqui de crítica aos insensatos em geral. Neste viés de interpretação, comumente aceito pelos críticos e comentadores do pensamento senequiano, temos a compreensão que a hostilidade dirigida às mulheres é, na verdade, um artifício retórico para disseminar preceitos morais ou uma contundente crítica aos costumes. Assim, nosso autor teria como alvo os insensatos, os que cometem erros oriundos de um mau juízo ou a sociedade degenerada e, portanto, não necessariamente ou exclusivamente as mulheres. Nesta linha de análise, podemos compreender algumas das passagens de Sêneca em relação à mulher como apenas mais uma crítica àqueles que vivem em desacordo com a natureza, àqueles que perseguem bens que não possuem valor em si. Isto é, a crítica de Sêneca deve ser, portanto, pensada como uma crítica endereçada a todos aqueles que vivem de modo vicioso, imprudentes e imperitos que, independentemente do sexo, cor, classe social ou posição, devem ser rechaçados, uma vez que subvertem sua verdadeira natureza ao agir tendo em vista valores indiferentes, e não buscando a virtude, único

\footnotetext{
28 GRAHN-WILDER, Gender and Sexuality in Stoic Philosophy, p. 183.

${ }^{29}$ FAVEZ, "Les opinions de Sénèque sur la femme”, p. 339.

30 SÊNECA, Helv. 14,2.

31 "Por isso eu acho o cúmulo do efeminado a frase daquele homem...". In: SÊNECA, Ep. 70, 6. Igualmente em Ep. 80, 8, Ep. 114, 3 e Ep. 45,2.

32 SÊNECA, Constant. I, 1. Em latim: "Tantum inter Stoicos, Serene, et ceteros sapientiam professos interesse quantum inter feminas et mares non inmerito dixerim, cum utraque turba ad uitae societatem tantundem conferat, sed altera pars ad obsequendum, altera imperio nata sit."
} 
valor realmente digno de ser perseguido. Esta é a posição, por exemplo, de Favez ${ }^{33}$, que afirma que Sêneca é realmente muito rude com as mulheres, mas não exclusivamente com elas. Sêneca é rude com todos aqueles que não vivem de modo racional, segundo o comentador. De fato, algumas das passagens do autor romano permitem tal interpretação. Vejamos o texto a seguir:

Nenhum animal chora por longo tempo a perda de seus filhos a não ser o homem, que permanece ligado à sua dor e não se aflige tanto quanto o que experimenta, mas quanto ele estabeleceu. Para que tu saibas, entretanto, que isto não é natural, deixar-se abater pelas dores, a mesma perda fere mais as mulheres que os homens, mais os bárbaros do que os homens de raça mansa e civilizada, mais os ignorantes que as pessoas cultas. Com efeito, todas as coisas que receberam força da natureza conservam-na igual em todos os seres. É evidente que não é natural o que é variável. O fogo queimará pessoas de todas as idades, cidadãos de todas as cidades, assim homens como mulheres; o ferro mostrará sua propriedade de cortar sobre todos os corpos: por quê? Porque tais propriedades lhes foram dadas pela natureza, que não faz distinção de pessoas. Um sente diversamente do outro a pobreza, o luto, o desprezo, segundo o influenciou o costume e o tornou fraco e intolerante a ideia presumida de coisas terríveis, mas que realmente não são terríveis. ${ }^{34}$

Estamos diante, portanto, de uma afirmação universal das capacidades de homens e mulheres, bárbaros e cidadãos romanos, mas que, ao mesmo tempo, expõe diferenças e características que, por influência dos costumes, erro de juízo ou, nas palavras do autor, "incapacidade de achar a atuação indicada em cada circunstância" 35 , os fazem suscetíveis de críticas e retaliações morais. Há, neste sentido, uma natureza racional presente em todo e qualquer ser humano, sendo ele homem ou mulher. E isto, como sabemos, está plenamente de acordo com a filosofia estoica. A natureza é, em última instância, a mantenedora desta universalidade invariável que permite, ao menos em potência, que todos os seres tenham igual chance de ascender à vida feliz. Às mulheres é, definitivamente, resguardada a possibilidade de ascese e aperfeiçoamento moral, bem como para qualquer outro.

O que faz com que mulheres e bárbaros sejam mais frequentemente acometidos pelo vício e pelas paixões? Teriam eles naturęa diversa? Seriam privados da universalidade da razão? De acordo com tal passagem e tal viés de interpretação, não. Segundo Sêneca, esta diferença se explicaria, por exemplo, pelos diferentes costumes de povos e nações, por seus diferentes graus de corrupção ${ }^{36}$. Seria esta diferença, por exemplo, que permitiria a divergência de reação de dois agentes diante de um mesmo objeto. Isto é, pode-se entender que, por causa dos diferentes costumes, seria possível explicar que, diante de um mesmo infortúnio, um homem, um bárbaro ou uma mulher, reagiriam diferentemente, uns de modo racional, de modo apropriado, outros não. Se há esta variabilidade nas ações e comportamentos, ela não deve, portanto, ser atribuída a uma natureza distinta de homens e

\footnotetext{
${ }^{33}$ FAVEZ, "Les opinions de Sénèque sur la femme”, p. 342.

${ }^{34}$ SÊNECA, Consolatio ad Marciam. VII, 2-4.

35 SÊNECA, Ep. 94, 32

36 SÊNECA, Ep. 122, 17.
} 
mulheres, visto que, retomando as palavras de Sêneca, "todas as coisas que receberam força da natureza conservam-na igual em todos os seres. É evidente que não é natural o que é variável." Assim, diz Sêneca na Consolação a Márcia, que tudo o que é natural é igual para todos os homens. Ademais, nas Cartas a Lucilio, diz nosso autor, ao defender os preceitos ${ }^{37}$ da filosofia, que no homem a "índole natural não está extinta, mas apenas obnubilada e reprimida", sendo plenamente possível seu aperfeiçoamento moral. É, neste sentido, a má escolha, influenciada ou não pelos maus costumes, que levam os homens [e mulheres] a viver de modo antinatural, precipitando-os ao sofrimento e à infelicidade. Tendo em vista tal afirmação, podemos dizer que, para Sêneca, o exercício da virtude é muito mais ligado à vontade (voluntas) do que propriamente às características naturais distintivas, como sexo, por exemplo. Ser virtuoso é, em última instância, assentir ${ }^{38}$ corretamente e, no plano ético dos deveres médios (kathekonta/officia), cumprir com excelência o papel que a Natureza nos determinou. Como sabemos, o assentimento constitui uma das faculdades centrais da doutrina estoica tanto no tocante da fundamentação de sua teoria do conhecimento, bem como no âmbito moral, uma vez que o assentimento precede o impulso que leva a qualquer ação. Há, portanto, um aspecto voluntário no assentimento, passível de ser influenciado pelos costumes, a partir do qual pode-se inferir que os homens [e as mulheres] são plenamente responsáveis por suas paixões, por seus sentimentos, desvarios e loucuras. Fazendo com que suas fraquezas e loucuras não passem de assentimentos errôneos dados às representações ${ }^{39}$. Portanto, neste primeiro viés interpretativo, se existe alguma diferença entre os homens e mulheres particulares, ela não seria uma diferença relativa à potencialidade de agir de modo justo e, consequentemente, de alcançar a felicidade. Não se trata de uma diferença de potências, mas sim pode ser compreendida enquanto relativa à efetiva prática das ações virtuosas ${ }^{40}$. Diz Pimentel:

Como estoico que é, porém, Sêneca reconhece à mulher o direito e apontalhe o dever de, como qualquer ser humano, construir dia-a-dia a uirtus, e de modo algum considera que ela seja incapaz de abraçar o difícil caminho do aperfeiçoamento constante que a doutrina do Pórtico propõe. Apenas parece julgar que elas, as mulheres, têm de lutar com redobrados esforços para vencer a muliebris impotentia (Helv. 14, 2), a incapacidade de dominar as paixões e a irracionalidade que normalmente as caracteriza. Mas não considera de forma alguma que lhes seja vedado o acesso à sapientia nem que lhes seja impossível a rejeição dos uitia. ${ }^{41}$

Em outro trecho, diz a mesma autora:

\footnotetext{
37 Praecepta. C.f. SÊNECA, Ep. 94 e 95.

$38 \mathrm{O}$ assentimento, segundo Volke, é formado a partir de um verbo que, em sua origem significa "o fato de estar de acordo com alguém e evoca a ideia de um escrutínio onde se deposita o mesmo voto que outro votante" (VOELKE, L'idée de volonté dans le stö̈cisme, p. 31).

39 Como nos diz Laurand: “Assim, se os estoicos proclamam o aspecto voluntário desta apreciação, eles sublinham a fraqueza e a loucura daquele que doa seu assentimento ao falso, ou simplesmente ao provável (o assentimento é nomeado então opinião) ele que é de fato plenamente responsável por sua loucura, ou, o que dá no mesmo, de sua ignorância, aquele que é incapaz de nuançar a adesão normal às representações catelépticas" (LAURAND, Le vocabulaire des stoïciens, p. 13).

40 SÊNECA, Ep. 94, 31 e 94, 56.

${ }^{41}$ PIMENTEL, "Estoicismo e figuras femininas em Séneca", p. 263.
} 


\begin{abstract}
Muitas são as mulheres que se igualam aos homens na depravação e no vitium, são estas as figuras que, por contraste luminoso, demonstram que, ainda que o estoicismo seja uma rigida ac virilis sapientia (Helv.12,4) e elas sejam mulheres e tenham de vencer a sua imbecillitas, não lhes faltará, se o quiserem, robur animi para conseguirem atingir o supremo bem que só a wirtus representa. ${ }^{42}$
\end{abstract}

No entanto, tal viés de interpretação não nos responde tudo e não nos fornece suficientes elementos para compreender afirmações diretamente ofensivas, por assim dizer, direcionadas às mulheres. Há ainda todo um conjunto de afirmações de Sêneca que, além de contraditórias com os princípios da universalidade da razão, ainda ratificaram, no decorrer da história, a construção de uma "identidade" feminina passional e distanciada da razão, como já exposto no texto. Assim, devemos propor uma segunda direção de interpretação, nos detendo naquelas passagens do texto senequiano que, infelizmente, não podemos admitir que sejam amparadas plenamente nas premissas estoicas. É verdade que Sêneca não é rude exclusivamente com as mulheres, mas é igualmente verdade que existem passagens em seu texto que são expressão pura e simples de sexismo. Analisemos, por exemplo, mais apuradamente algumas passagens. Diz o autor romano:

Há muita diferença, afirmo, entre o ânimo sublime e o soberbo. A iracúndia não medita nada de amplo e de belo. Ao contrário, parece-me próprio de uma alma prostrada e infeliz, consciente de sua fraqueza, sofrer constante dor, como os corpos ulcerados e enfermos que gemem ao mais leve toque. Assim, a ira é um vício típico, sobretudo, da mulher e da criança. 'Mas acomete inclusive os homens.' Realmente, há também homens com um temperamento pueril e feminino. ${ }^{43}$

Para Sêneca, é preciso ter consciência que algumas almas, sobretudo e tipicamente as almas das mulheres, são fracas, pueris, passionais, viciosas, prostradas e infelizes. Por outro lado, existem as almas fortes, ativas e dotadas de um vigor viril. Um claro contraste é apresentado. Diz o filósofo:

Tais coisas [chorar e se abater] vemos acontecer às mulheres toda vez que uma leve suspeita de perigo as aflige. Os seus deveres o homem [uir] virtuoso cumprirá imperturbado, intrépido; e assim fará o que é digno de um homem de virtude: nada fará que seja indigno de um homem. Meu pai será assassinado: irei defendê-lo; foi assassinado: buscarei justiça, porque é necessário, não porque me dói. ${ }^{44}$

Vemos que, sobretudo no De ira, há a constante ligação entre, de um lado, o autodomínio, a racionalidade e a virilidade e, de outro, os excessos, a entrega desenfreada às paixões e os comportamentos lascivos, efeminados e passionais. Neste sentido, constrói-se

42 PIMENTEL, "Estoicismo e figuras femininas em Séneca”, p. 268.

${ }^{43}$ SÊNECA, De Ira, I, 20, 3.

44 SÊNECA, De Ira, I, 12, 1-2. 
um estereótipo, infelizmente em voga até os dias atuais, que associa as mulheres aos juízos de pouca clareza, de racionalidade mitigada. Portanto, suas opiniões não merecem igual respeito. Veja o que diz o autor nas Epistolas à Lucilio:

Em que te ajudará nisto a filosofia, essa arte excelsa que a tudo sobreleva? Precisamente em levar-te a querer agradar mais a ti do que ao vulgo, a avaliar a qualidade e não o número, das pessoas que emitem juízos sobre ti, a viver sem temor dos deuses ou dos homens, a poder vencer a adversidade ou a pôr-lhe cobro. Por outro lado, se eu te vir andar famoso nas bocas do mundo, se à tua entrada, como à de histriões no palco, ressoarem vivas e palmas, se por toda a cidade mulheres e crianças te tecerem louvores, como não hei de eu lamentar-te, sabendo como sei qual a via para se obter tal favor?! $!^{45}$

Alguns trechos ainda trazem algumas das críticas sexistas direcionadas às mulheres, constituindo reproduções vulgares de opiniões sociais romanas. Muitas destas reprovações morais estão associadas à questão dos indiferentes, tais como beleza, riqueza, etc. Diz Sêneca, por exemplo, ao criticar o adultério no casamento, que somente mulheres deformadas são $\operatorname{castas}^{46}$. Isto é, somente as desprovidas de beleza física agem virtuosamente. Afirmação incoerente com o estoicismo, já que sabemos que a posse ou não destes atributos, destes indiferentes, não impede o exercício de uma ação correta, virtuosa e, portanto, racional. Seja bonita ou feia, rica ou pobre, livre ou escrava, uma mulher pode viver de acordo com a natureza. Ou Sêneca acaso aceitaria, diante de uma falta moral ou de uma ação infeliz cometida por um homem qualquer, a justificativa de sua beleza ou feiura?

Enfim, como balanço geral desta representação das mulheres realizada pelo filósofo romano, estamos de acordo que Sêneca, em muitos de seus textos, reconhece a possibilidade de exercício da plena racionalidade oferecida às mulheres. Neste sentido, é elogiável a postura do autor quando "reconhece às mulheres uma grandeza de alma e amiúde conseguida" ${ }^{47}$. No entanto, mesmo que haja o reconhecimento da mulher enquanto ente capaz de, como qualquer outro, alcançar a felicidade por meio da vida virtuosa, o filósofo peca ao atrelar ao universo feminino uma argumentação muitas vezes ligada à opinião comum difundida na sociedade romana do primeiro século de nossa era ${ }^{48}$ e, lamentavelmente, de modo contraditório com a própria doutrina estoica. Deste modo, Sêneca inegavelmente contribuiu para a construção de um estereótipo, uma tipificação ou "identidade da mulher" que é passional e, portanto, distante da racionalidade almejada pelo estoicismo. Tal contribuição, somada aos séculos de dominações e preconceitos, fundamenta falaciosos critérios que, ainda hoje, justificam a depreciação intelectual das mulheres.

\footnotetext{
45 SÊNECA, Ep. 29, 12.

46 SÊNECA, Ben. III, 16, 3. Argumentum est deformitatis pudicitia.

47 PIMENTEL, "Estoicismo e figuras femininas em Séneca", p. 268.

48 Por exemplo como expresso em SÊNECA, Ep. 63, 13. Ver ainda Tito Lívio (Ad. Urbe) 34, 2, 2 ou Tácito (Annais, I, 4). Vide a escolha do vocabulário do autor, suas expressões e interjeições ao longo de sua obra. Além disso, deve-se levar em conta que os deveres médios estão indexados ao papel social que se desempenha, assim, mulheres terão determinados deveres, homens outros, etc. Não é nosso tema discutir aqui se tais deveres são progressistas ou não, tão somente elucidar a ambígua representação das mulheres no pensamento senequiano.
} 


\section{Referências bibliográficas}

A.A. LONG \& D. N. SEDLEY. Les philosophes hellénistiques. Vol. II. Les Stoïciens. Paris: Flammarion, 2001.

AIKIN, S. e MC-GILL-RUTHERFORD, E. "Stoicism, Feminism and Autonomy". In: Symposion, 1, I. (2014). pp. 9-22.

ARNIM, Hans Von. Stoici antichi, tutti i frammenti. Introduzione, traduzione, note e apparati a cura di Roberto Radice; presentazione di Giovanni Reale. Milano: Bompiani, 2002.

DIÔGENES LAÊRTIOS. Vida e doutrina dos filósofos ilustres. Tradução do Grego de Mário da Gama Kury. Brasília: Editora Universidade de Brasília, 2008

FAVEZ, C. "Les opinions de Sénèque sur la femme”. In: REL (Révue des Etudes Latines), 1938. pp. 335-345.

GRAHN-WILDER, Malin. Gender and Sexuality in Stoic Philosophy. New York: Palgrave Macmillan, 2018

LAURAND, V. Le vocabulaire des stoïciens. Ed. Ellipses. Paris : 2002.

La politique Stoïcienne. Paris : PUF, 2005.

MANNING, C. E. "Seneca and the stoics on the equality of the sexes". In: Mnemosyne. Vol. 26, Fasc. 2 (1973). Pp. 170-177

MÜLLER, R. Les Stoüciens: La liberté et l'ordre du monde. VRIN. Paris: 2006.

PIMENTEL, Maria Cristina. "Aliquando sexum egressa (Tac. Ann. 16.10): quando a mulher transcende a fraqueza do seu sexo". In: Cristina Santos Pinheiro, Anna Martina Emonts, Maria da Glória Franco, Maria João Beja (coords.), Mulheres: Feminino, Plural. Funchal: Nova Delphi, 2013. pp. 15-36.

"Estoicismo e figuras femininas em Séneca". In: Brotéria, 158 (2004), pp. 251-268.

RADICE, Roberto. "Oikeiosis": ricerche sul fondamento del pensiero stoico e sulla sua genesi. Milano: Ed. Vita e Pensiero, 2000

SÊNECA. Cartas à Lucílio. Tradução, prefácio e notas de J. A. Segurado e Campos. $4^{a}$ Edição. Lisboa: Fundação Calouste Gulbenkian, 2009.

Cartas Consolatórias (Consolatio ad Marciam; Consolatio ad Helviam ; Consolatio ad Polybium). Tradução de Cleonice Furtado Mendonça Van Raij. Campinas: Pontes, 1992.

Sobre a brevidade da vida; Sobre a Firmeza do Sábio. (De Brevitate Vitae; De Constantia

Sapientis). Tradução de José Eduardo S. Lohner. São Paulo: Penguin Classics Companhia das Letras, 2017. 
. Sobre a Ira; Sobre a tranquilidade da alma. (De Ira; De Tranquilitate Animi). Tradução de José Eduardo S. Lohner. São Paulo: Penguin Classics Companhia das Letras, 2014.

Sobre a tranquilidade da alma / Sobre o Ócio. Tradução, notas e apresentação de José Rodrigues Seabra Filho. Ed. Bilíngue. São Paulo: Nova Alexandria, 2001.

Tratado sobre a clemência (De Clementia). Tradução, introdução e notas de Ingeborg Braren. Petrópolis: Editora Vozes, 1990.

TÁCITO. Anais. Tradução e prólogo de Leopoldo Pereira. Rio de Janeiro: Ediouro, 1967.

TITO LIVIO. História de Roma. (Ad Urbe Condita Libri). São Paulo: Paumape, 1989.

VEYNE, P. “L'homossexualité à Rome”. In: Communications, 35, 1982. Sexualités occidentales. Contribution à l'histoire et à la sociologie de la sexualité, pp. 26-30.

VOELKE, A.-J. L'idée de volonté dans le stö̈isme. Paris: PUF, 1973. 